\title{
Accounting for Sustainability: Practical Insights
}

Anthony Hopwood, Jeffery Unerman and Jessica Fries (eds). Earthscan, London, 2010. xxvi + 258 pp. Price $£ 25$ (paperback). ISBN 978-1-84971-067.

The back-cover blurb claims that this compilation of eight case studies, all UK or EU-based, 'show[s] in detail how accounting for sustainability works in practice'. In summary: not well. Contributions by 21 accountants, six of them professors, show that if this is the best that business can do, then accounting is not yet contributing much to sustainability, even with the imprimatur of His Royal Highness The Prince of Wales, Prince Charles.

The book is not really about social or environmental accounting in any meaningful way. The heads of five different professional accounting bodies provided front-cover blurbs, and not one claims that the book is about accounting. It sets out what eight organisations claim to do under the banner of corporate social responsibility. The organisations are all in the public and services sectors: supermarket chain, energy utility, local council, government environment agency, telecommunications supplier, bank, insurance company and drug company. No mining, petrochemical, logging, fishing, ranching, manufacturing, infrastructure or building companies. The indicators they use are almost all internal. More recycling, less paper, double-sided copying, staff involvement, days sick, workplace injuries, schools promotions (pp. 79, 90, 108109, 111-114, 158-161, 220-221, 223).

Some are proud of global programmes which pledge, for example, to hire black people, women, ethnic minorities and disabled people, and not to use child or slave labour. One would hope so. They also plan to send less hazardous waste to landfills. But why are they sending any? They intend to investigate reports of fraud (p. 109). But isn’t that a legal requirement?

Only some say what they have actually achieved and they do not seem to have been very successful. The local government, for example, spent over a million pounds a year on water, rising continuously from 2005/2006 to 2008/2009; and of this, 
0.0006\% was for 'sustainability' expenses (p. 124); and most of that was to run a conference. No kidding!

The drug company was driven by two factors. It had to comply with the US Sarbanes-Oxley Act (p. 224). And along with 38 other drug companies, it tried to take legal action against South Africa for distributing AIDS treatments, provoking a huge public backlash in its home country. The insurance company introduced video conferencing and low-flush toilets (p. 200). The telecommunications company was worried about brand damage if its international suppliers used child labour (pp. 162-164). The supermarket chain says sustainability means 'continuing to be able to supply the products that we wish to supply or [sic] that our customers want' - an interesting dichotomy in itself.

So as ecologists, can we ignore this volume completely? Sadly, no. We really do need accurate and comprehensive environmental accounting at all scales from individual organisations to worldwide. And we really do not have it, partly because it is difficult, but mainly because we do not spend as much effort as we do on financial accounting. Large-scale ecosystem valuation attempts are useful politically, but they are not environmental accounts. Measures of biodiversity loss are a form of environmental accounting, but not one which can be used to compare individual corporations. So we have a long way to go.

RALF BUCKLEY

Director, International Centre for Ecotourism Research Gold Coast campus, Griffith University Qld 4222, Australia

Telephone: +61.7.55528675

Fax: +61.7.55528895

E-mail: r.buckley@griffith.edu.au 